\title{
Atom Probe Tomography of Al-Cu Precipitation in an Al-5 at.\%Cu Thin Film
}

\author{
C. Srivastava*, G.B. Thompson*, D. Reinhard**, J. Sebastian**, T.J. Prosa**, D.J. Larson**, Z.T. \\ Reddy*, S. Gupta*, W. Butler*** and M.L. Weaver* \\ *University of Alabama, Department of Metallurgical \& Materials Engineering, $2017^{\text {th }}$ Ave, A129 \\ Bevill Building, Tuscaloosa, AL 35487-0202 \\ **Imago Scientific Instruments, 6300 Enterprise Lane, Suite 100, Madison, WI 53719-1193 \\ *** University of Alabama, Department of Physics and Astronomy, $2017^{\text {th }}$ Ave, A205 Bevill \\ Building, Tuscaloosa, AL 35487-0202
}

$\mathrm{Al}-\mathrm{Cu}$ alloy thin films have found a variety of uses in microelectronics because of their simple processing and good electrical conductivity. In particular, the $\mathrm{Cu}$ additions have shown to reduce electromigration effects that occur at high current densities in $\mathrm{Al}$ interconnections. The reduction of electromigration is associated with the segregation of $\mathrm{Cu}$ to grain boundaries within the $\mathrm{Al}$ matrix and the precipitation of $\mathrm{Al}-\mathrm{Cu}$ intermetallic phase(s) [1]. Recently, Choi et al. [2] reported atom probe studies of an $\mathrm{Al}-2 \mathrm{at} . \% \mathrm{Cu}$ film. In this work, $\mathrm{Cu}$ segregation to grain boundaries was clearly evident and they did not observe the formation of any metastable intermetallic phases commonly observed in bulk Al-Cu for similar compositions. In the present work, we have investigated richer $\mathrm{Cu}$ concentrations and the interaction of different underlayers on the precipitation in an $\mathrm{Al}-\mathrm{Cu}$ thin film.

A series of $\sim 20 \mathrm{~nm}$ thick $\mathrm{Al}-5 \mathrm{at} . \% \mathrm{Cu}$ films were co-continuously sputter deposited from two elemental targets with a working gas of UHP Ar at 2.5 mTorr. Prior to sputtering, the base chamber was $<10^{-7}$ Torr. The films were sputter deposited onto pre-fabricated Si tips that were either bare Si (with native surface oxide) or had a Pt or NiFe film on the surface of the tip which served as an underlayer for the $\mathrm{Al}-\mathrm{Cu}$ film. Once the $\mathrm{Al}-\mathrm{Cu}$ film was deposited, the specimen was annealed at $240^{\circ} \mathrm{C}$ for 4 hours under a flowing $\mathrm{Ar}+5 \% \mathrm{H}_{2}$ environment to facilitate precipitation of the $\Theta$-phase $\left(\mathrm{Al}_{2} \mathrm{Cu}\right)$. Post-annealing, the coated tips were placed in a Local Electrode Atom Probe (LEAP) [3]. The needle was cryogenically cooled to $115 \mathrm{~K}$ and field evaporated at $200 \mathrm{kHz}$ at a $1 \%$ field evaporation rate.

As can be seen in Fig. 1, we clearly see the depletion of $\mathrm{Cu}$ within the $\mathrm{Al}$ matrix and the formation of two $\mathrm{Al}_{2} \mathrm{Cu} \Theta$-phase precipitates. The precipitates exhibited a disk shape morphology that expands laterally within the film and grew up towards the free surface and substrate interface. Choi et al. [2] reported that for their lower concentrations of $\mathrm{Cu}$, the second phase formation or segregation of $\mathrm{Cu}$ was not present at these surfaces. At these annealing temperatures, the native oxide at the $\mathrm{Si}$ substrate appears sufficient to impede any $\mathrm{Si}$ interdiffusion within the Al-Cu matrix. Similarly, it was found that a chemically abrupt interface was present between the annealed Al-Cu film and the $\mathrm{NiFe}$ underlayer. This materials' interface is critical in providing potential leads to magnetic related sensors. Unlike these two films, the Pt underlayer significantly interdiffused into the Al-Cu film upon annealing, as shown in Fig. 2. Interestingly, the $\mathrm{Cu}$ concentration increases and the $\mathrm{Pt}$ concentration decreases near the surface of the film even though $\mathrm{Pt}$ and $\mathrm{Cu}$ have complete solid solubility (at elevated temperatures). In contrast, $\mathrm{Al}$ and $\mathrm{Pt}$ only exhibit solid solubility at concentrations greater than $\sim 90 \mathrm{at} . \% \mathrm{Pt}$. Surprisingly, this level of either $\mathrm{Pt}$ or $\mathrm{Cu}$ is well within the supersaturation for the formation of Al-based intermetallic(s). There was no evidence of phase 
separation or clustering of these elements in the Al matrix. Although this anneal was able to promote thermally activated diffusion of Pt into the matrix, the kinetics of any secondary phase formation must be significantly high and/or hindered. Consequently, this system, at the annealing temperatures investigated, is unable to achieve a favored phase. The role of $\mathrm{Pt}$ in kinetically limiting phase separation in $\mathrm{Al}-\mathrm{Cu}$ films will be addressed in this presentation.

\section{References:}

[1] XY Liu, W Xu SM Foiles and JB Adams, Applied Physics Letters 72 (1998) 1578.

[2] P-P Choi, T Al-Kassab and R Kirchheim, Scripta Materialia 53 (2005) 323.

[3] T.F. Kelly and D.J. Larson, Mat. Char. 44 (2000) 59.

[4] The UA authors gratefully acknowledge NSF-ECS-0529369 for supporting this research.

(a)

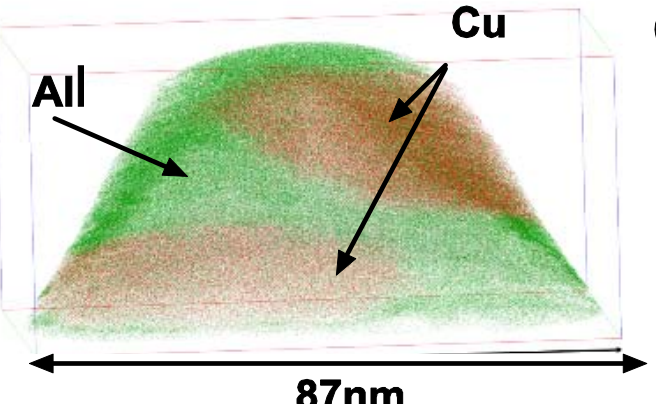

(b)

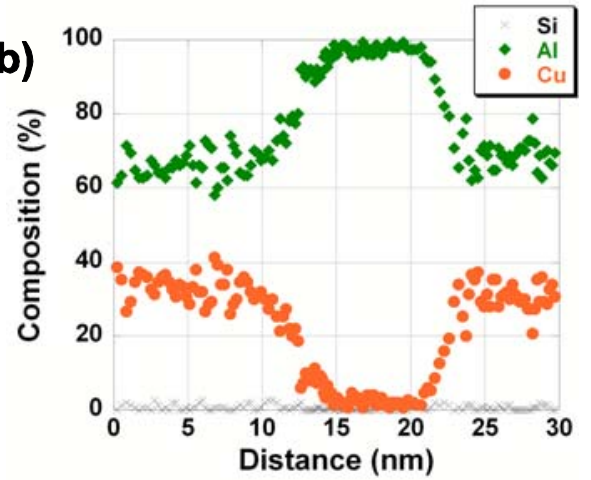

Fig.1: (a) Atom map reconstruction of the $\mathrm{Al}$ and $\mathrm{Al}_{2} \mathrm{Cu}$ phases within the film (b) Composition profile through the two precipitates
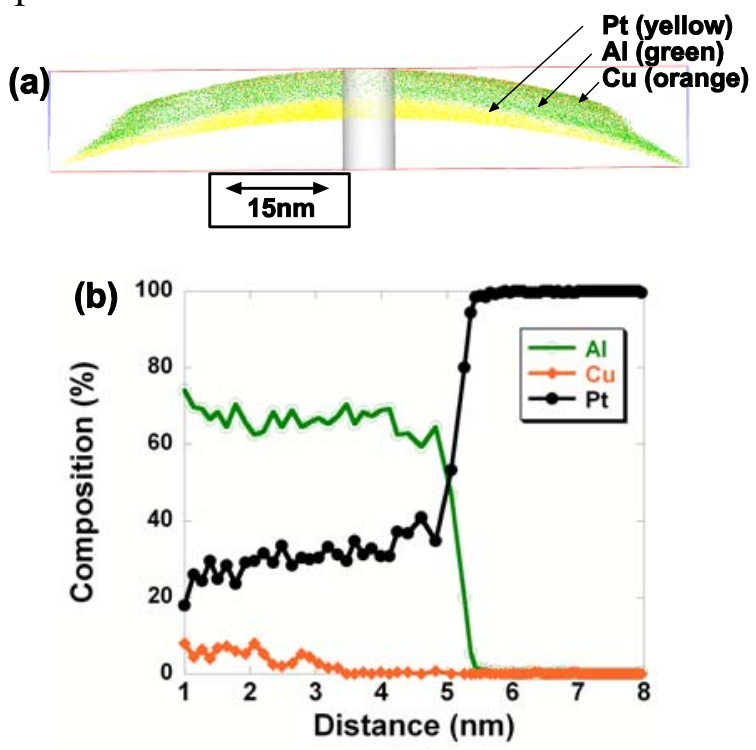

Fig.2: (a) Atom map reconstruction of the interdiffused $\mathrm{Pt}$ underlayer within the Al-Cu film. Note the lack of phase separation (b) Compositional profile through the film and underlayer. 